Supplement of Hydrol. Earth Syst. Sci., 24, 4675-4690, 2020

https://doi.org/10.5194/hess-24-4675-2020-supplement

(c) Author(s) 2020. This work is distributed under

the Creative Commons Attribution 4.0 License.

(c) (1)

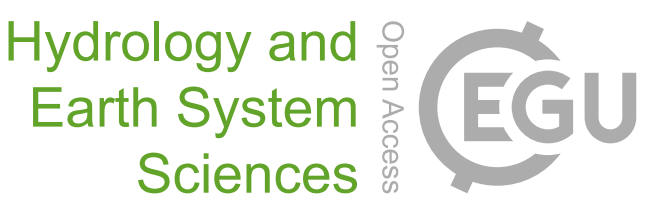

Supplement of

\title{
Throughfall isotopic composition in relation to drop size at the intra-event scale in a Mediterranean Scots pine stand
}

Juan Pinos et al.

Correspondence to: Pilar Llorens (pilar.llorens@idaea.csic.es)

The copyright of individual parts of the supplement might differ from the CC BY 4.0 License. 


\section{Supplementary material}

Table S1. Meteorological characteristics and isotopic composition of open rainfall and throughfall for the 21 events during the study period, May 2018 to July 2019.

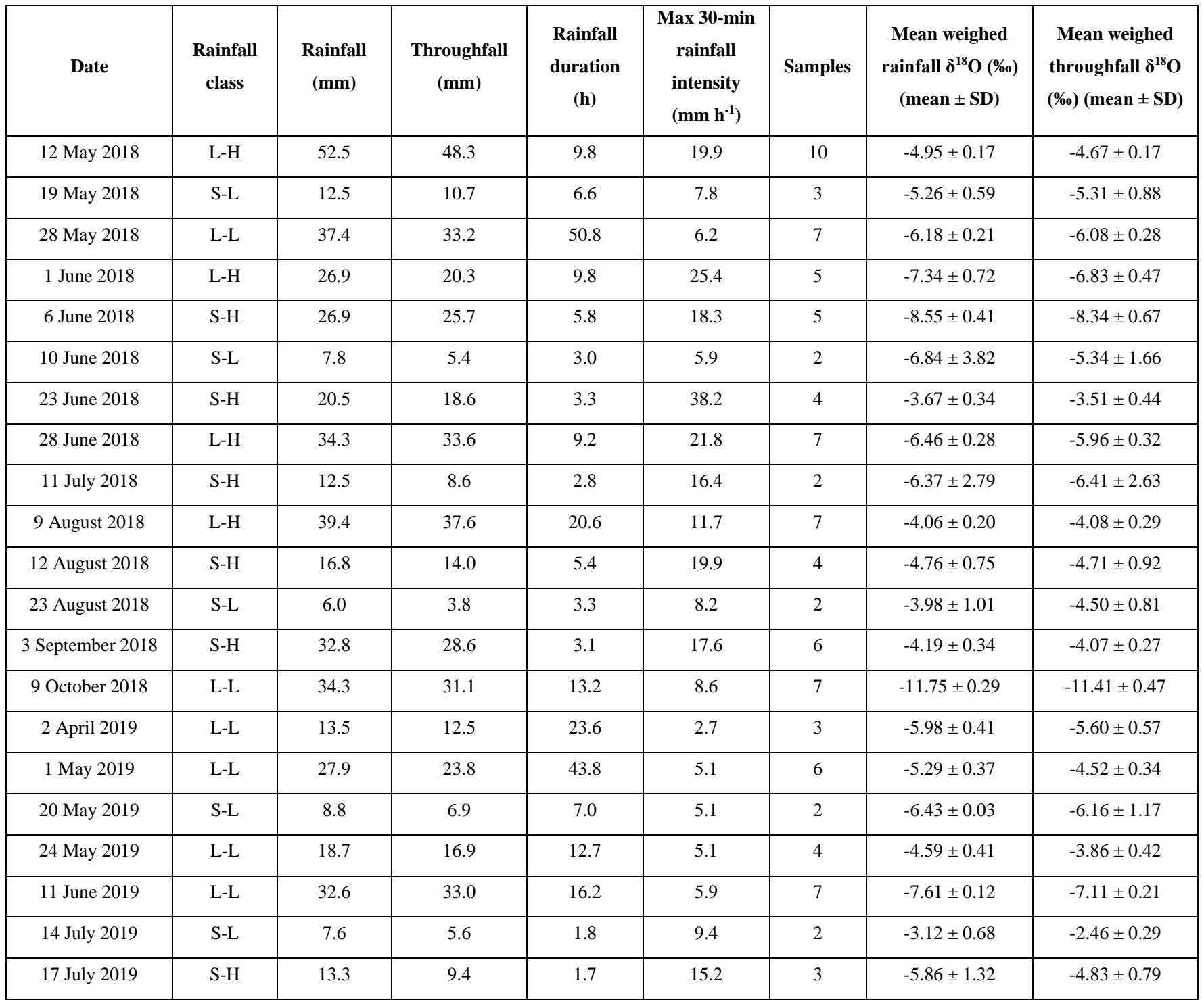


Table S2. Average percentage of throughfall types for each of the rainfall classes. SP: splash throughfall, FR: free throughfall, and DR: canopy drip.

10

\begin{tabular}{|c|c|c|c|}
\hline Rainfall class & SP (\%) & FR (\%) & DR (\%) \\
\hline L-H & 16.9 & 21.3 & 61.8 \\
\hline S-L & 14.3 & 16.4 & 69.3 \\
\hline S-H & 19.0 & 25.0 & 56.4 \\
\hline L-L & 14.6 & 13.5 & 72.0 \\
\hline
\end{tabular}

15 

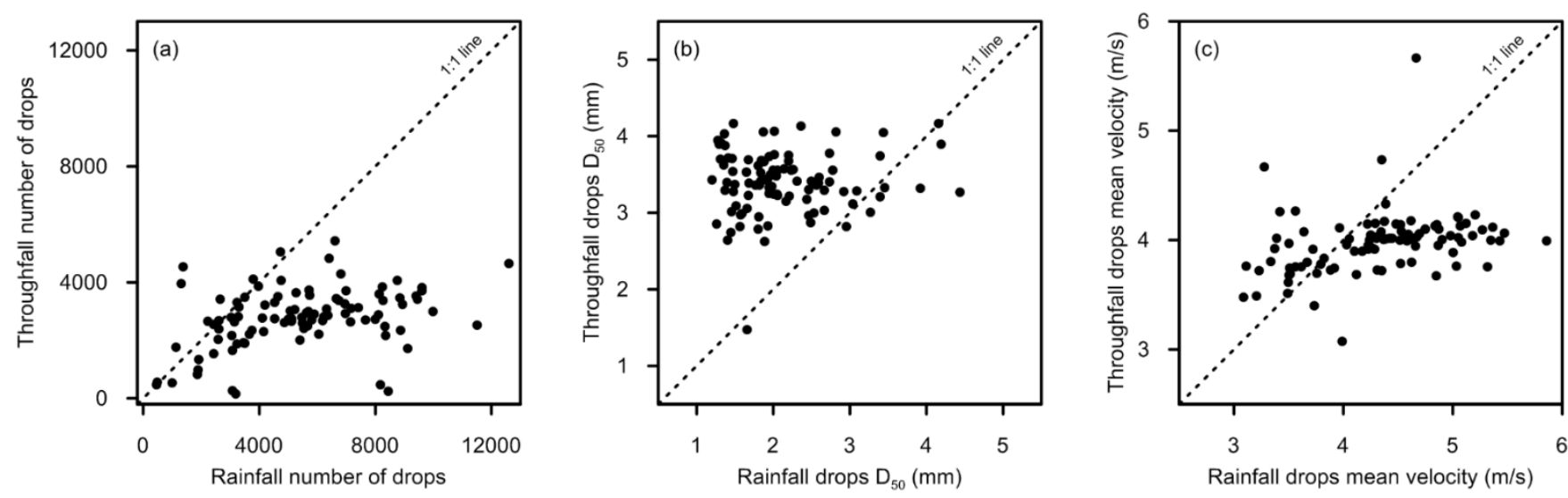

30 Figure S1. Relationship between open rainfall and throughfall for: (a) number of drops, (b) median volume drop diameter $\left(\mathrm{D}_{50}\right)$ and (c) drops' mean velocity. 

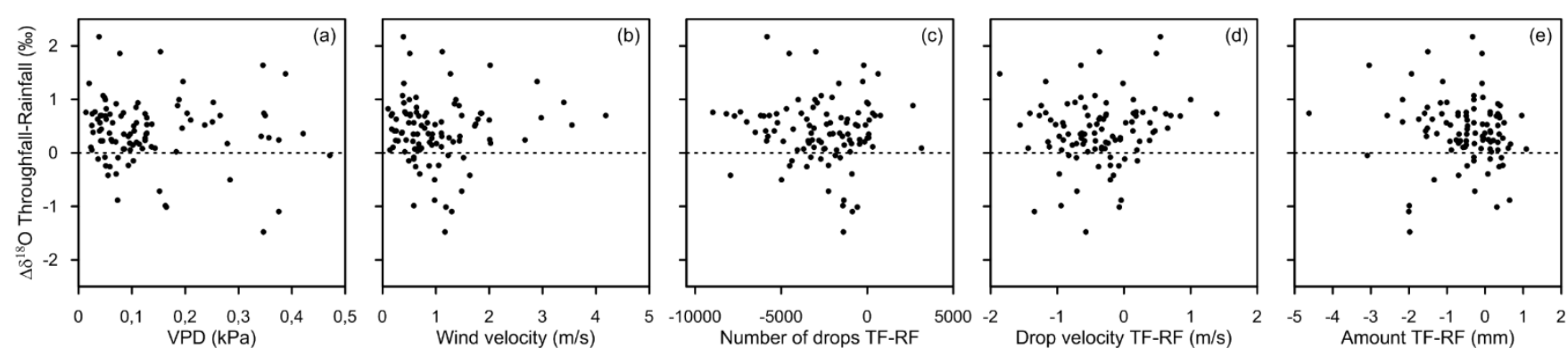

Figure S2. Isotopic shift variability $\left(\delta^{18} \mathrm{O}_{\mathrm{TF}-\mathrm{RF}}\right)$ versus: (a) vapor pressure deficit, (b) mean wind velocity, (c) differences in number of drops, (d) differences in mean drop velocity and (e) differences in amount per sample. 

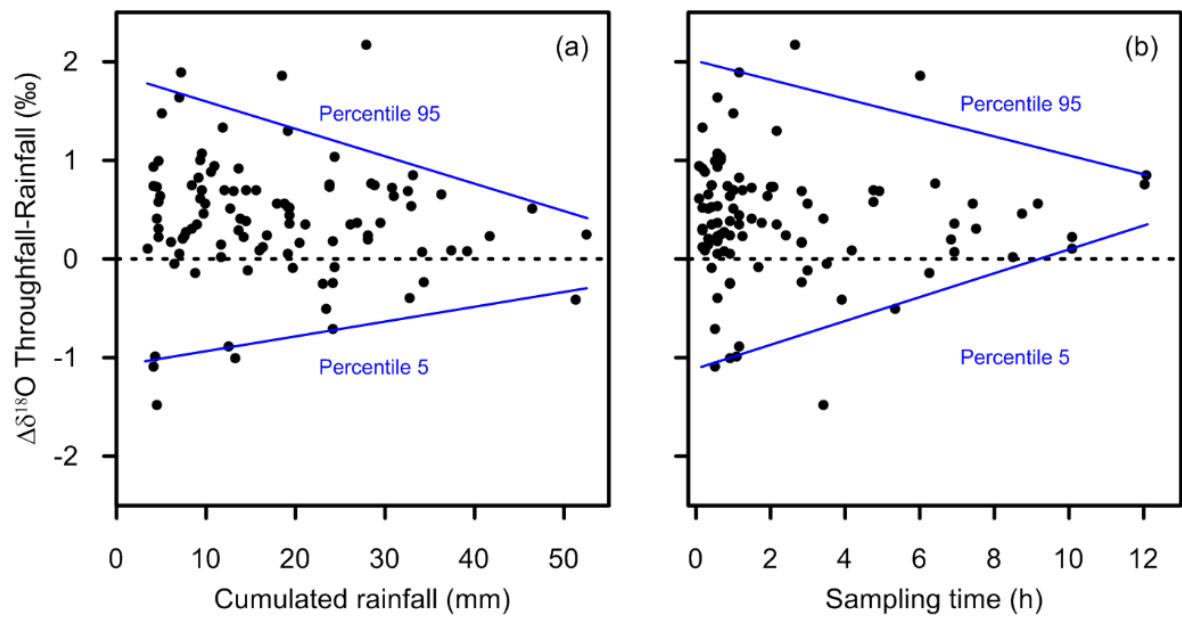

70 Figure S3. Isotopic shift variability $\left(\delta^{18} \mathrm{O}_{\mathrm{TF}-\mathrm{RF}}\right)$ versus: (a) cumulative rainfall throughout the rainfall event and (b) sampling time (i.e. time each $5 \mathrm{~mm}$ sample took to be filled). 